\title{
Innovation during Disruption: Implementing a Nurse Anesthesiology Educational Program during a Pandemic
}

\author{
Catherine Horvath, DNP, CRNA ${ }^{1 *}$, Marjorie Everson, PhD, CRNA ${ }^{2}$, Victoria Goode, PhD, CRNA ${ }^{3}$, and
} Bruce A Schoneboom, PhD, CRNA, FAAN ${ }^{4}$

\begin{abstract}
${ }^{1}$ Assistant Professor and Program Director of the Doctor of Nursing Practice Nurse Anesthesiology Track at Johns Hopkins School of Nursing, Baltimore MD, USA

${ }^{2}$ Lecturer in the Doctor of Nursing Practice Nurse Anesthesiology Track at Johns Hopkins School of Nursing, Baltimore, MD, USA

${ }^{3}$ Faculty Associate Professor and faculty in the Doctor of Nursing Practice Nurse Anesthesiology Track at Johns Hopkins School of Nursing, Baltimore, MD, USA

${ }^{4}$ Associate Dean of Practice, Innovation and Leadership at Johns Hopkins School of Nursing, Baltimore, MD, USA
\end{abstract}

\begin{abstract}
Background: The COVID-19 public health emergency has created challenges for university educational programs due to state stay at home orders and campus closures.

Problem: The Johns Hopkins School of Nursing was scheduled to launch a new nurse anesthesiology program slated to be on-campus and in-person but this was plan was drastically altered by the pandemic induced prohibition of face-to-face activities at the university.
\end{abstract}

Approach: Re-engineer the nurse anesthesiology program's plan of study to provide high-quality distance education at an accredited distance education program.

\begin{abstract}
Outcomes: The nurse anesthesiology program was able to pivot to provide the first year of a three-year program via distance education. The nurse anesthesiology program matriculated its first cohort as scheduled as full-time students in high-quality coursework.
\end{abstract}

Conclusions: The pandemic crisis made it necessary to implement innovative strategies to successfully launch a new academic program.

Keywords

Nurse Anesthetists, Innovation, Distance Education, COVID-19

The healthcare system in the United States is strained. Stressors that affect the quality of care Americans receive in the U.S. healthcare system include: 1) Continued degradation and court challenges to the Patient Protection and Affordable Care Act of 2010; 2) Feforms at the federal level to change the incentives from fee for service to a more value-based system of care; 3 ) The aging population [1], including healthcare workers, that require more healthcare services; 4) Over 50 million Americans who suffer from chronic pain [2]; 5) The over prescription of opioids and the opioid overdose epidemic; and 6) Shortages of quality healthcare providers including anesthesia providers like Certified Registered Nurse Anesthetists (CRNAs). In addition, the COVID-19 pandemic has also placed an enormous stress on the healthcare system across the country and particularly in the state of Maryland, where CRNAs have been critical in providing care to acutely respi- ratory compromised patients. Currently there is only one civilian CRNA educational program contributing to the state

*Corresponding author: Catherine Horvath, DNP, CRNA, Assistant Professor and Program Director of the Doctor of Nursing Practice Nurse Anesthesiology Track at Johns Hopkins School of Nursing, 525 N. Wolfe Street, Suite 461, Baltimore, MD 21205, USA, Tel: 202-538-1790

Received: August 15, 2020

Accepted: September 03, 2020

Published online: September 05, 2020

Citation: Horvath C, Everson M, Goode V, et al. (2020) Innovation during Disruption: Implementing a Nurse Anesthesiology Educational Program during a Pandemic. J Nurs Pract 3(1):148150

Copyright: (C) 2020 Horvath C, et al. This is an open-access article distributed under the terms of the Creative Commons Attribution License, which permits unrestricted use, distribution, and reproduction in any medium, provided the original author and source are credited. 
Citation: Horvath C, Everson M, Goode V, et al. (2020) Innovation during Disruption: Implementing a Nurse Anesthesiology Educational Program during a Pandemic. J Nurs Pract 3(1):148-150

of Maryland CRNA workforce. As a result, both the University of Maryland and the John Hopkins Healthcare System are experiencing shortages of CRNAs. Due to these shortages of CRNAs in the Johns Hopkins Healthcare System (JHHS) a partnership was developed between the Anesthesiology Department and the School of Nursing (JHSON) to re-establish a CRNA educational program to address this shortage. This collaboration will: (1) Prepare highly trained and competent CRNAs for the JHHS and the state of Maryland at the doctoral level; (2) Develop nurse anesthesia faculty for the future; (3) Increase collaboration and dialogue with CRNAs in the region; and (4) Advance an ecosystem for fostering science in nurse anesthesia. According to U.S. News and World report, dated January 8, 2019, nurse anesthetists' rank \#3 in the best health care jobs category and \#5 best job overall.

\section{Nurse Anesthesiology Track}

An integrated curriculum, including distance education, was developed for the doctor of nursing practice (DNP) nurse anesthesiology track (NAT) at JHSON. The integrated curriculum entails students taking didactic classes throughout the program, including during the clinical training phase as opposed to front-loaded nurse anesthesiology programs which deliver all didactic courses prior to students entering the clinical phase of the curriculum. The NAT curriculum was originally composed of 38 DNP course credits (43\%) which are delivered via the distance education format. The NAT sought and received approval from its accrediting body, The Council on Accreditation of Nurse Anesthesia Educational Programs (COA) [3], to provide distance education courses. The COA requires distance education courses and distance education programs ( $50 \%$ or greater of curriculum delivered via distance education) to meet the same standards as traditionally delivered education courses. The NAT at JHSON received their initial accreditation in January 2020.

\section{Impact of COVID}

On December 31, 2019, China reported a cluster of cases of pneumonia, later identified as caused by a novel coronavirus, severe acute respiratory syndrome coronavirus 2 (SARSCoV-2) which causes coronavirus disease (COVID-19). The United States recorded its first case on January 20, 2020 [4] and by March 11, 2020 the World Health Organization (WHO) had declared the outbreak a pandemic [5]. In response to the virus's arrival and spread, cities and states began to issue stay at home orders, healthcare systems began to prepare for infected patients, and universities began transitioning to remote instruction.

On March 10, 2020 Johns Hopkins University (JHU), like many universities across the nation, made the decision to suspend all in-person classroom instruction and transition to remote instruction. At that time, the change to remote instruction was expected to be in effect until May 21, although much uncertainty lingered [6]. Just a few days later, on March 14 , JHU leadership announced access to all campus buildings was restricted, and instruction would continue to be delivered remotely/online until further notice [6]. As a brand-new program created to embrace on-campus activities and due to launch May 11, 2020, innovation was required to assure con- tinued student enrollment and seamless progression into the plan of study.

Recognizing the serious impact that COVID-19 was having on programs, the COA, which accredits nurse anesthesia programs in the United States and Puerto Rico, recognized that programs may need to implement strategies different from typical operating procedures. The COA normally requires program to apply to offer distance education courses and a distance education program, where $50 \%$ or more of the total curriculum in the plan of study is offered via distance education [3]. The COA demands this to ensure that all programs and courses achieve the same outcomes as traditional education offerings. However, for this unprecedented time, the COA provided temporary approval for programs to use distance education to accommodate educational offerings without going through the COA approval process while restrictions are in place for face-to-face teaching [3].

An additional consequence of the COVID-19 crisis is the negative impact on the mental health of healthcare providers, especially those on the front-line of care. During this unprecedented time of fear and stress, nurses are at high risk for mental health issues like anxiety, depression and post-traumatic stress. According to author Lai, et al. in study of frontline health care workers, nurses and women in China who had engaged in direct diagnosis, treatment, and care of patients with COVID-19 were at higher risk of symptoms of depression, anxiety, insomnia, and distress [7].

A requirement of matriculation into nurse anesthesiology educational programs is to have spent at-least 1-year as a registered nurse in an intensive care unit. Therefore, all current students entering a program would have just left the bedside of intensive care units, the battleground for COVID patient care. Whether having personally taken care of COVID-positive patients, or working within a strained uncertain healthcare system, students of a program are likely negatively mentally affected.

To help assist nurses, including student registered nurse anesthetists, 58 nursing organizations, including the professional organization of 55,000 certified nurse anesthetists and student nurse anesthetists, wrote a letter of concern to the White House and administration about the negative psychological health and well-being of nurses and other frontline staff during the COVID-19 public health emergency, and asked the Administration to take these concrete steps to provide psychological first aid [8].

\section{Program Innovation}

With the threat of COVID-19, faculty of the NAT needed to problem solve the impact to the inaugural 2020 cohort. The curricular plan of study and student mental health strain needed to be considered. This was especially crucial as the timing of COVID-19 impact coincided with potential relocation for several students.

While the JHSON NAT was approved for 38 out of 88 credits to be in the format of online instruction, the program was not considered a distance education (DE) program as stipulated by the COA. We examined the program of study to ascer- 
tain whether we could reconfigure courses to allow the 2020 cohort to delay their move to Baltimore until January 2021.

Simultaneously, the imminent threat of the virus was being evaluated by the COA through guidance from regulatory agencies such as the U.S. Department of Education and Council on Higher Education Accreditation for its impact on nurse anesthesia programs (NAP) both didactically and clinically. University in-person instruction was halted, and alternatives ways were needed to innovate in order to continue with the proposed plan of study. The virus and the shortage of personal protective equipment was making it difficult for NAT students to continue in a business as usual environment. To facilitate ongoing instruction, the COA provided a "temporary broad approval to programs to allow for the delivery of course via DE to SRNAs on a temporary basis, without going through the COA DE approval process" [3]. Thus, the faculty, along with the consultation of the Dean and Vice Dean developed a curriculum change for the summer of 2020 that replaced on campus face to face instruction with an all online format. This curriculum change was approved by the DNP curriculum committee to allow the entire first year to be delivered in an online format. The new delivery of the program of study would deliver 48 credits of the 88 credits in an online format. While the summer 2020 coursework would be covered by the temporary approval granted via the COA due to the unprecedented impact of COVD-19, it represented only a temporary change for $\mathrm{DE}$. This curriculum change was considered a substantial change to the program and required an official DE application to the COA. The DE was submitted in May 2020 and is pending approval from the COA.

In addition to the curricular modifications, faculty planned to implement strategies to strengthen the wellness of the student cohort. NAT orientation day included a brief discussion about the importance of wellness and self-care during the program, with a guided breathing and stretching session. Lectures in a Professional Aspects of Nurse Anesthesiology Practice course incorporated multiple breaks, introducing short yoga, meditation, and stretching. Virtual chats over coffee were planned.

The COA will be monitoring and surveying programs for continued needs in response to COVID-19. We as a faculty will also monitor our innovation with the change to the program of study to ascertain its impact on both the students from a curricula perspective but also through a survey on its outcome of ease of transition while beginning a doctoral program during a worldwide pandemic.

\section{Conclusion}

Johns Hopkins University has a long history of innovation. As the first research-focused university in the country, innovation was part of its establishment. The university takes its name from the 19th-century Maryland philanthropist Johns Hopkins, an entrepreneur and abolitionist with Quaker roots who believed in improving public health and education in Baltimore, which has a predominantly African-American community. Founded in 1876, the university revolutionized higher education by integrating teaching and research. Although the Johns Hopkins hospital has a long history of training nurses and nurse anesthetists, the Johns Hopkins University School of Nursing wasn't established until 1989. Since that time the school has also been leader and innovator. Some examples include: 1) Transitioning the entry to nursing to the master's degree; 2) Creating an online infrastructure including instructional designers and course support personnel that is state of the art; 3) Creating novel DNP/PhD dual degree programs; and 4) Re-establishing an educational program in Nurse Anesthesiology. This new program in Nurse Anesthesiology was very fortunate in that the school had already developed online support. That made the transition to re-engineer the plan of study easier so that the first year could be delivered online due to the COVID-19 pandemic. This change will likely be permanent, if student feedback is positive. Benefits of this hybrid model include potential savings for students to delay a move to Baltimore by one year. So far, students have adapted well to the online environment, which is not surprising as younger generations are much more comfortable learning and socializing in the digital environment.

\section{Conflict of Interest}

No author list above has a conflict of interest.

\section{Acknowledgements}

None to list.

\section{References}

1. Population bulletin: Aging in the United States (2020) Population reference bureau, USA.

2. CDC national center for injury prevention and control (2018) 2018 Annual surveillance report of drug-related risks and outcomes.

3. Council on Accreditation of Nurse Anesthesia Educational Programs- COA (2020) FAQ's and statement regarding meeting clinical requirements.

4. Holshue ML, DeBolt C, Lindquist S, et al. (2020) First case of 2019 novel coronavirus in the United States. New England Journal of Medicine 382: 929-936.

5. World Health Organization-WHO (2020) Coronavirus disease 2019: Situation report-51.

6. Johns Hopkins University HUB (2018) Johns Hopkins transitions to online instruction amid COVID concerns.

7. Lai J, Ma S, Wang Y, et al. (2020) Factors associated with mental health outcomes among health care workers exposed to coronavirus disease 2019. JAMA Network Open 3: e203976.

8. American Association of Nurse Anesthetists (2020) COVID-19 Mental health support for frontline nurses: Urgent request letter to the White House and administration.

DOI: $10.36959 / 545 / 376$ 